\title{
Inflamação na doença renal crônica: papel de citocinas
}

\author{
Inflammation in chronic kidney disease: the role of cytokines
}

\begin{abstract}
Autores
Heloisa R Vianna ${ }^{1}$

Cristina Maria

Bouissou Morais

Soares $^{2}$

Marcelo STavares ${ }^{2}$

Mauro Martins

Teixeira $^{3}$

Ana Cristina Simoes e

Silva ${ }^{2}$

${ }^{1}$ Programa de Pós-graduação em Ciências da Saúde - Saúde da Criança e do Adolescente da Faculdade de Medicina da Universidade Federal de Minas Gerais - UFMG. 2Unidade de Nefrologia Pediátrica - Departamento de Pediatria - Hospital das Clínicas da UFMG.

${ }^{3}$ Departamento de Bioquímica e Imunologia - Instituto de Ciências Biológicas da UFMG.
\end{abstract}

Data de submissão: 29/04/2011 Data de aprovação: 14/08/2011

Correspondência para: Ana Cristina Simões e Silva Avenida Bernardo Monteiro 1.300/1.104

Belo Horizonte (MG) -

Brasil

CEP: 30150-281

E-mail: acssilva@hotmail.

com

O referido estudo foi realizado na Unidade de Nefrologia Pediátrica do Departamento de Pediatria da Faculdade de Medicina da UFMG.

Os autores declaram a inexistência de conflitos de interesse.

\section{Resumo}

A doença renal crônica (DRC) é um grave problema de saúde pública cuja prevalência tem aumentado nos últimos anos. Apresenta caráter progressivo e está associada à elevada morbidade e mortalidade. Inúmeros fatores estão associados à instalação e progressão da DRC, tais como obesidade, hipertensão arterial e diabetes mellitus. Além desses fatores, existem evidências de inflamação na fisiopatologia da DRC. Diversas citocinas e quimiocinas têm sido detectadas no plasma e urina de pacientes em estágios precoces da DRC e também relacionadas às complicações da doença. A expressão desses mediadores e a lesão renal sofrem interferência de fármacos como inibidores de enzima conversora de angiotensina (ECA), estatinas e antagonistas de receptores de citocinas. A modulação da resposta imuno-inflamatória pode se tornar alvo para tratamento da DRC. O objetivo deste artigo de revisão foi resumir as evidências científicas do papel da inflamação na DRC, destacando-se os efeitos de citocinas e quimiocinas.

Palavras-chave: Citocinas. Quimiocinas. Inflamação. Falência renal crônica.

\section{INTRODUÇÃO}

A doença renal crônica (DRC) tem aumentado, de forma epidêmica em todo o mundo, sobretudo em função do aumento global na prevalência das principais causas de DRC como hipertensão arterial sistêmica (HAS), diabetes mellitus (DM) e obesidade. ${ }^{1-3}$ Segundo dados do National Health and Nutrition Examination Surveys (NHANES), a prevalência de DRC (excluindo a DRC terminal) nos Estados Unidos foi de 13,1\% no

\section{Abstract}

Chronic kidney disease (CKD) is a serious public health problem whose prevalence has increased in the last few years. Its progression is associated with high morbidity and mortality. Several factors are associated with the onset and progression of CKD, such as obesity, hypertension and diabetes mellitus. Beyond these factors, there is evidence of a pathophysiological role for inflammation in CKD. Several cytokines and chemokines have been detected in the plasma and urine of patients at early stages of CKD, and have also been related to CKD complications. The expression of these mediators and renal injury may be influenced by drugs such as angiotensin-converting enzyme inhibitors, statins and antagonists of cytokine receptors. Modulation of the immune-inflammatory response can become a target for CKD treatment. The aim of this study was to review the scientific evidence on the role of inflammation in CKD, especially the effects of cytokines and chemokines.

Keywords: Cytokines. Chemokines. Inflammation. Kidney failure, chronic. período de 1999-2004. ${ }^{1,3}$ A prevalência de DRC estágios 3 a 5 apresentou-se em torno de $5 \%$, baseando-se nos dados do NHANES 1999-2004 nos Estados Unidos e em estudos realizados na Austrália, China e Índia. ${ }^{1,3}$ Associado a isso, o número de pacientes com DRC terminal que necessita terapia dialítica ou transplante renal, também tem aumentado significativamente nos países desenvolvidos e em desenvolvimento. ${ }^{3}$ Em janeiro de 2009, segundo dados da Sociedade Brasileira de 
Nefrologia, o número estimado de pacientes em diálise no Brasil foi de 77.589, o que representou um aumento de 6,7\% em relação ao ano de 2007 (73.605 pacientes) e de $31,2 \%$ em relação ao ano de 2004 (59.104 pacientes)..$^{4-5}$ As estimativas das taxas de prevalência e de incidência de doença renal crônica em tratamento dialítico em nosso país foram de 405 e 144 pacientes por milhão da população, respectivamente. ${ }^{5} \mathrm{O}$ número estimado de pacientes que iniciaram tratamento em 2009 foi de 27.612 e a taxa anual de mortalidade bruta foi de $17,1 \%$. $^{5}$

Recentemente, tem-se considerado o papel da inflamação subclínica na progressão das doenças crônico-degenerativas. ${ }^{6-7} \mathrm{~A}$ inflamação é um processo fisiológico em resposta a diferentes estímulos como infecções, alterações físico-químicas e antigênicas ou danos traumáticos. A resposta inflamatória necessita ser precisamente regulada, uma vez que deficiências ou excessos dessa resposta estão diretamente relacionados com mortalidade e morbidade. ${ }^{8}$. Nesse contexto, existem evidências de ativação do sistema imune em estágios precoces e tardios da DRC.9-11 Por outro lado, alguns estudos sugerem uma relação negativa entre níveis circulantes de mediadores de inflamação e o estágio da doença. ${ }^{10}$ Sabe-se também que, em pacientes portadores de DRC terminal ou não, a presença de inflamação é um fator preditor independente de mortalidade..$^{7,12-14}$

Há que se considerar também que a doença cardiovascular (DCV) é, atualmente, a principal causa de morbidade e mortalidade em portadores de DRC. ${ }^{7,13,15}$ Estudos mostram que a inflamação aumenta o risco cardiovascular e a mortalidade dos pacientes com DRC terminal. ${ }^{13,14}$ Postula-se ainda que os fatores de risco tradicionais para a DCV tais como HAS, DM, dislipidemia e obesidade não seriam suficientes para elevar de tal forma a incidência de complicações cardiovasculares nos pacientes com DRC terminal. ${ }^{16}$ Sendo assim, o processo inflamatório, associado aos efeitos do estresse oxidativo, da resistência à insulina e da disfunção endotelial são considerados fatores de risco para DCV nos pacientes com DRC. ${ }^{17}$

A via final comum da DRC é caracterizada pela progressiva fibrose glomerular e/ou túbulo-intersticial, lesão capilar peritubular por hipóxia e perda de funcionamento dos néfrons por esclerose glomerular e atrofia tubular, independentemente do mecanismo primário que desencadeou a lesão renal. ${ }^{18}$ Nesse processo fisiopatológico de progressão da lesão renal tem sido cada vez mais detectada a participação dos mecanismos inflamatórios. ${ }^{19}$
Este artigo de revisão tem por objetivo resumir as evidências científicas referentes ao possível papel de mediadores imuno-inflamatórios na fisiopatologia da DRC, independentemente da etiologia. Nesse sentido, o papel da inflamação na progressão da DRC é evidenciado nas glomerulopatias, doenças nas quais o processo inflamatório é classicamente reconhecido, bem como nas malformações congênitas dos rins e trato urinários, enfermidades cujo principal mecanismo de lesão era tradicionalmente relacionado ao processo de obstrução mecânica. O potencial de algumas citocinas e quimiocinas como biomarcadores de progressão da DRC, tais como o fator de transformação de crescimento do tipo beta (TGF- $\beta$ ), a proteína quimiotáxica para monócitos do tipo 1 (MCP-1/ CCL2) e a interleucina-8 (IL-8/CXCL8) também são enfatizadas.

\section{INFLAMAÇÃO E DOENÇA RENAL CRÔNICA}

De forma genérica, considera-se inflamação ou processo inflamatório a resposta do organismo a qualquer tipo de agressão sofrida. ${ }^{8}$ Entende-se como agressão qualquer processo capaz de causar lesão celular ou tecidual. Esta resposta padrão é comum a vários tipos de tecidos e é mediada por diversas substâncias produzidas pelas células danificadas e células do sistema imunitário que se encontram eventualmente nas proximidades da lesão. ${ }^{6,8,20} \mathrm{~A}$ ativação do sistema imune, decorrente da lesão tecidual, quando ocorre de forma exacerbada, com aumento excessivo do processo inflamatório, pode favorecer a instalação e a progressão de doenças. ${ }^{6}$ A exacerbação da resposta inflamatória leva à perda de tolerância periférica aos componentes dos próprios tecidos, que se tornam antigênicos e desencadeiam inflamação local. ${ }^{20} \mathrm{~A}$ estimulação imunológica é contínua e o processo se prolonga até a completa destruição tecidual. ${ }^{21}$ Assim, em consequência da ativação inicial, as substâncias mediadoras da resposta inflamatória agem sobre as células alvo, que podem estar localizadas em qualquer compartimento do corpo, levando a diferentes processos mórbidos, tais como a DRC. ${ }^{20-22}$

Especificamente em relação ao tecido renal, a inflamação participa de forma ativa dos mecanismos de progressão da lesão renal em doenças de diversas etiologias. 9,17,18,21,22 Por exemplo, nas doenças de acometimento glomerular, postula-se resumidamente a seguinte sequência de eventos: $:^{3,9,18,22}$

1) a lesão glomerular persistente produz hipertensão capilar, aumento da filtração glomerular e passagem de proteínas para o fluido tubular; 
2) a proteinúria de origem glomerular aumenta a produção de angiotensina (Ang) II e promove liberação de mediadores inflamatórios (citocinas e quimiocinas), que induzem o acúmulo de células mononucleares no interstício renal;

3) o recrutamento inicial de neutrófilos é substituído por macrófagos e linfócitos $\mathrm{T}$, que desencadeiam resposta imune, produzindo nefrite intersticial;

4) as células tubulares respondem a este processo inflamatório por meio de lesão da membrana basal e pela transição epitelial-mesenquimal se transformando em fibroblastos intersticiais;

5) os fibroblastos formados produzem colágeno, que, por sua vez, lesa os vasos e os túbulos renais, eventualmente determinando a formação de uma cicatriz acelular.

Além das glomerulopatias e doenças autoimunes, nas quais o papel da inflamação é evidente, os estudos têm mostrado que, também em outras etiologias de DRC, a resposta inflamatória contribui para a progressão da lesão renal. , $^{3,9,17,18,21,22}$ Nesse contexto, o papel do processo inflamatório tem sido evidenciado em malformações congênitas do trato urinário, tais como as uropatias obstrutivas (para revisão, ver Chevalier et al. ${ }^{23}$ ). De forma resumida, os seguintes mecanismos fisiopatológicos têm sido propostos para explicar a progressão da DRC nas uropatias obstrutivas (Figura 1):

1) aumento do diâmetro e proliferação das células tubulares dos rins obstruídos;

2) estiramento mecânico das células tubulares pelo processo obstrutivo que promove recrutamento de células inflamatórias e liberação de citocinas e quimiocinas no tecido renal;

3) apoptose das células tubulares seguida de apoptose do compartimento intersticial;

4) transição epitelial-mesenquimal das células tubulares e intersticiais levando à formação de fibroblastos;

5) proliferação progressiva de fibroblastos e recrutamento contínuo de células inflamatórias;

6) síntese de colágeno pelos fibroblastos com consequente deposição de matriz extracelular e fibrose renal.

Figura 1. Células e mediadores envolvidos na progressão da doença renal crônica (adaptado de Chevalier et al. ${ }^{23}$ ).

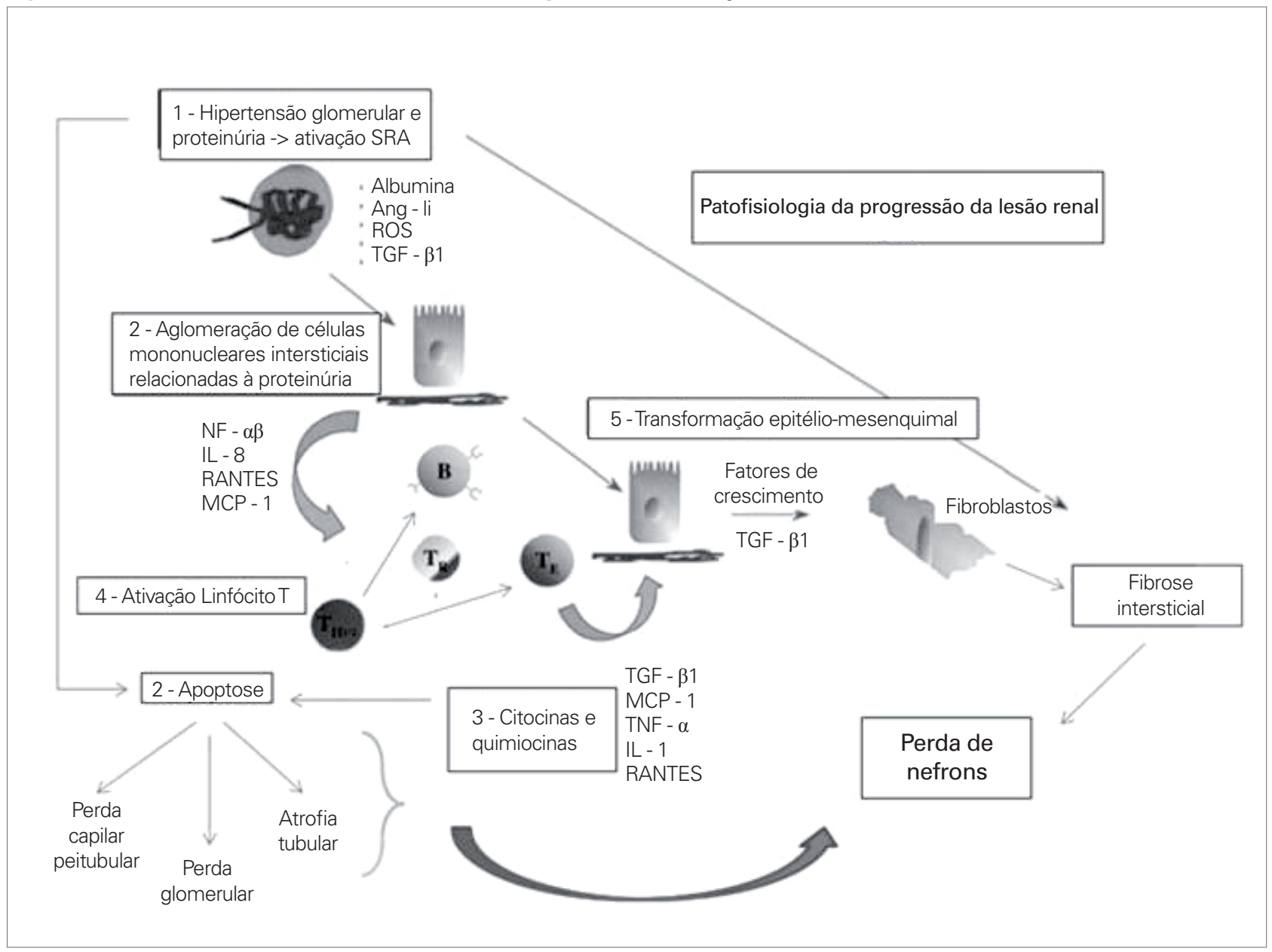


Diversos estudos clínicos corroboram a importância da inflamação na fisiopatologia da DRC. 7, 10,12-14,16,17,22 O estado inflamatório crônico observado na DRC se associa à elevação dos níveis séricos de proteínas inflamatórias de fase aguda, como a proteína $\mathrm{C}$ reativa (PCR), e de uma variedade de mediadores imuno-inflamatórios, tais como citocinas, componentes do sistema de complemento, prostagladinas e leucotrienos. ${ }^{24-31}$ Dessa forma, a mensuração dos níveis circulantes de PCR, dos mediadores imuno-inflamatórios, bem como a avaliação de polimorfismos dos genes que codificam esses mediadores imuno-inflamatórios têm mostrado que os pacientes com DRC apresentam um fenótipo pró-inflamatório que se acentua na medida em que a lesão renal segue rumo a seu estágio terminal. ${ }^{24-31}$ Nesse sentido, os estudos mostram a detecção de níveis elevados de PCR ultrassensível (entre 47,6 e 76,2 nmol/L) em 30 e $60 \%$ de todos os pacientes portadores de DRC nos Estados Unidos (EUA), Canadá e países europeus (para revisão, ver Krane e Wanner ${ }^{25}$ ). Além disso, tem sido mostrado que alguns polimorfismos de genes que codificam mediadores inflamatórios estão associados a pior evolução de pacientes com DRC. ${ }^{24}$ Para exemplificar, Rao et al. mostraram que a substituição G/C no códon 25 do gene que codifica o TGF- $\beta$ associou-se ao risco aumentado de morbimortalidade cardiovascular em pacientes com DRC terminal. ${ }^{24}$ Acredita-se, assim, que fatores genéticos, ambientais e culturais como o hábito alimentar influenciem no perfil inflamatório dos pacientes com DRC. ${ }^{13,14,24,25}$

Por outro lado, os mecanismos pelos quais a inflamação produz deterioração da função renal ainda não estão totalmente elucidados. Sabe-se que os mediadores imuno-inflamatórios modulam a função endotelial, adesão e migração das células circulantes do sistema imune (monócitos, leucócitos ou neutrófilos) para o interstício, além de serem capazes de ativar fibroblastos residentes. ${ }^{18-}$ ${ }^{19}$ A deterioração da função renal tem sido associada ao aumento dos níveis séricos de PCR, de citocinas e dos receptores solúveis para estas citocinas nos diferentes estágios da DRC. 17,28-30,32,33 Postula-se que as citocinas, ao interagirem com seus receptores localizados na membrana celular, regulem a transcrição de inúmeros genes e determinem modificações do comportamento das células presentes no tecido renal. ${ }^{29}$ Dentre as citocinas próinflamatórias que têm sido associadas à fisiopatologia da doença renal destacam-se a interleucina-1 (IL-1), interleucina-6 (IL-6) e o fator de necrose tumoral- $\alpha$ (TNFa). ${ }^{30} \mathrm{Na}$ população adulta, há evidências de ativação do sistema imune em estágios precoces da DRC. ${ }^{10,11}$ Níveis elevados de PCR foram associados a todas as causas de mortalidade em pacientes nos estágios 3 e 4 de DRC. ${ }^{32,33}$ Foi também detectada associação entre os níveis de PCR e citocinas pró-inflamatórias, especialmente IL- $6 .{ }^{34-37} \mathrm{Em}$ crianças portadoras de DRC secundária às mais diversas causas, as excreções urinárias de endotelina (ET-1), de TGF- $\beta 1$ e do fator de crescimento derivado do endotélio vascular (VEGF) mostraram-se significativamente elevadas em relação aos controles pareados. ${ }^{38} \mathrm{O}$ aumento da excreção desses mediadores correlacionou-se com a diminuição da taxa de filtração glomerular (TFG) e foi mais evidente nos pacientes com uropatias obstrutivas, refletindo o impacto da lesão túbulo-intersticial sobre a função renal global..$^{38}$

\section{Citocinas e ouimiocinas}

Citocinas são proteínas solúveis, de baixo peso molecular, secretadas pelos leucócitos e outras células do organismo, principalmente em resposta a estímulos antigênicos, que atuam como mensageiros do sistema imune. As citocinas podem receber denominações específicas que se referem ao tipo celular que predominantemente as sintetizam e aos seus mecanismos de ação. Sendo assim, as citocinas predominantemente sintetizadas por fagócitos mononucleares são denominadas monocinas, enquanto as produzidas principalmente por linfócitos são linfocinas. Citocinas que agem em outros leucócitos são denominadas interleucinas (IL). As IL estão envolvidas na resposta e na apresentação de antígenos, principalmente pelos linfócitos T auxiliares. ${ }^{39}$ As citocinas com função de controlar o tráfego basal e inflamatório de leucócitos por meio de quimiotaxia são chamadas de quimiocinas, ou seja, citocinas quimiotáxicas. ${ }^{39} \mathrm{~A}$ movimentação é propriedade fundamental das células imunes e as quimiocinas são importantes facilitadoras desse processo. Além da quimiotaxia, as quimiocinas apresentam efeito pró-angiogênico e promovem degranulação de leucócitos. Dessa forma, a resposta imune final consiste em uma combinação de funções biológicas. ${ }^{26}$

As duas principais famílias de quimiocinas são as quimiocinas CC, dotadas de dois resíduos de cisteína adjacentes e as quimiocinas CXC, dotadas de resíduos de cisteína separados por um aminoácido. ${ }^{39}$ As quimiocinas podem ser classificadas em induzíveis, quando sua síntese é estimulada por qualquer fator que altere a homeostase celular; e em constitutivas, que são responsáveis pelo tráfego leucocitário basal e pela formação da arquitetura de órgãos linfóides secundários. ${ }^{6}$

Conforme mencionado na seção anterior, existem evidências clínicas e experimentais que corroboram a 
participação de citocinas e quimiocinas em diferentes mecanismos delesãoao tecido renal. ${ }^{24-38}$ Especificamente no tecido renal, as citocinas induzem proliferação local de células tubulares e intersticiais, síntese de matriz extracelular, atividade pró-coagulante do endotélio, formação de espécies reativas de oxigênio e aumento da expressão de moléculas de adesão e lípides biologicamente ativos. ${ }^{24-31}$ A liberação de citocinas também se relaciona aos efeitos hemodinâmicos e locais da ativação do sistema renina angiotensina (SRA). A seguir, o papel da obesidade e do SRA na relação entre DRC e inflamação são sumariamente comentados.

\section{Obesidade, doença renal crônica e INFLAMAÇÃO}

A obesidade é um fator de risco independente para DRC. Pacientes norte-americanos obesos têm risco quatro vezes maior de desenvolver DRC que pacientes não obesos e, nesta mesma população, a hipertensão responde por $25 \%$ dos casos de DRC..$^{40}$ Sabe-se que a obesidade induz alterações fisiopatológicas que contribuem para a lesão renal. ${ }^{2} \mathrm{O}$ acúmulo de lípides nos macrófagos pode alterar o fenótipo dessas células e favorecer o surgimento de um ambiente pró-inflamatório responsável pelas modificações fisiopatológicas do rim associadas à obesidade. ${ }^{2}$ Diversas citocinas pró-inflamatórias produzidas pelo tecido adiposo e por células inflamatórias têm sido relacionadas às lesões renais induzidas pela obesidade. Dentre esses mediadores, merecem menção o inibidor da ativação do plasminogênio-1 (PAI-1), a quimiocina MCP-1 e a resistina. ${ }^{2}$ Os níveis circulantes dessas citocinas estão aumentados em pacientes com síndrome metabólica e se relacionam com resistência insulínica, aumento das lipoproteínas circulantes, aterogênese e trombogênese, efeitos esses que direta ou indiretamente afetam a estrutura e a função renal. ${ }^{2}$ Nesse contexto, Eddy et al. mostraram que o aumento da expressão do PAI-1, induzido no tecido adiposo e nas células glomerulares de pacientes obesos, é fator de risco independente para fibrose renal ao inibir a degradação local de matriz extracelular e recrutar células inflamatórias. ${ }^{41}$

Outro mecanismo provavelmente envolvido no desencadeamento da DRC, em pacientes obesos, é a formação aumentada de espécies reativas de oxigênio. ${ }^{42}$ Os níveis elevados de colesterol podem estimular a produção de superóxido que, por sua vez, contribuem para a disfunção renal observada em pacientes obesos. ${ }^{42} \mathrm{O}$ aumento dos radicais superóxido pode elevar a produção endógena da enzima superóxido desmutase e induzir, consequentemente, lesão renal por meio da redução da biodisponibilidade de óxido nítrico. ${ }^{42}$
O estresse oxidativo, a inflamação e a disfunção endotelial secundária favorecem a instalação e a progressão DRC. ${ }^{42}$ Knight et al. mostraram que tanto a sinvastatina, uma estatina, quanto o 4-hidroxi-tempol, uma substância com ação similar à enzima superóxido desmutase, apresentaram efeitos antioxidantes através da diminuição da produção de 8 -isoprostano em modelo animal de hipertensão e obesidade. ${ }^{43}$ Esses autores verificaram também que somente o tratamento com 4-hidróxi-tempol, e não com sinvastatina, promoveu redução da resposta inflamatória no tecido renal por meio de redução da excreção urinária da quimiocina MCP-1/CCL2 e da infiltração tecidual de macrófagos. Dessa forma, a redução da lesão renal de ratos obesos e hipertensos em resposta ao tratamento com 4-hidróxi-tempol se deve, pelo menos em parte, à inibição do processo inflamatório no tecido renal. ${ }^{43}$

\section{SistemA RENINA ANGIOTENSINA, DOENÇA RENAL CRÔNICA E INFLAMAÇÃO}

O SRA exerce papel central nos processos de sinalização intracelular das citocinas possivelmente modulando a resposta inflamatória associada à progressão da doença renal e a susceptibilidade para a disfunção cardiovascular. ${ }^{18}$ Polimorfismos genéticos do SRA e de citocinas podem determinar expressão alterada de citocinas inflamatórias e, consequentemente, promoverem a progressão da doença renal e o surgimento de alterações cardiovasculares em pacientes com DRC. ${ }^{24,44}$ A relação de todos os polimorfismos genéticos da via SRA-citocinas associados à progressão da DRC e às complicações cardiovasculares está além do escopo desta revisão (para revisão, ver a listagem completa que pode ser encontrada no sítio eletrônico do National Center for Biotechnology Information SNP databas $\left.e^{45}\right)$. Tais variações genéticas podem ser as responsáveis pelas diferenças observadas na progressão das disfunções renal e cardiovascular no paciente com DRC. 18,24,44

Para exemplificar a interação entre alterações genéticas do SRA e modulação da expressão de citocinas, Yvan-Charvet et al. detectaram aumento do RNA mensageiro para TNF- $\alpha$, IL-6 e IL-1 no tecido adiposo de camundongos com superexpressão do angiotensinogênio. ${ }^{46}$ Além disso, já foi mostrado que a Ang II é capaz de ativar células tubulares ou glomerulares e induzir a liberação de TGF- $\beta$, MCP-1/CCL2 e regulated on activation normal $T$ cell expressed and secreted RANTES/CCL5. ${ }^{47} \mathrm{O}$ SRA participa ativamente da regulação do tônus vasomotor e da proliferação celular, podendo afetar a função e estrutura renais, bem como 
promover alterações cardiovasculares. ${ }^{48}$ Ensaios experimentais e estudos clínicos têm mostrado que tanto a inibição da ECA quanto o bloqueio dos receptores angiotensinérgicos do tipo 1 (AT1) retardam a progressão da doença renal não só por controlarem a HAS como também por exercerem efeitos anti-inflamatórios, antiproliferativos a anti-oxidativos. ${ }^{47-52}$

Os tratamentos com inibidores da ECA e com bloqueadores do receptor AT1 da Ang II preveniram e/ou atenuaram a regulação para cima de diversos genes próinflamatórios em modelo experimental de nefrectomia sub-total. ${ }^{47}$ A redução dos níveis de TGF- $\beta 1$ em modelo animal, em pacientes transplantados renais e em portadores de nefropatia diabética também tem sido descrita após uso destas drogas. ${ }^{49-51}$ Amann, Tinzmann e Angelkort mostraram que o uso de inibidor de ECA, em diabéticos tipo 2 portadores de nefropatia, reduziu os níveis urinários de MCP-1/CCL2 e determinou melhora da função renal. ${ }^{51} \mathrm{O}$ bloqueio da Ang II também se mostrou capaz de reduzir excreção urinária de albumina oxidada, sem alterar a excreção urinária total de proteínas e os níveis pressóricos. ${ }^{42} \mathrm{~A}$ excreção urinária de albumina oxidada correlacionou-se positivamente com os níveis urinários de MCP-1/CCL2, reforçando a importância da interação entre inflamação e estresse oxidativo na progressão da DRC. ${ }^{52}$

\section{INFLAMAC̄̃̃O NA NEFROPATIA OBSTRUTIVA}

Conforme mencionado anteriormente, a DRC pode ser oriunda de diversas etiologias cujos mecanismos fisiopatológicos são, consequentemente, muito diferentes. ${ }^{3,18}$ As principais causas de DRC podem ser subdivididas em dois grandes grupos: congênitas e adquiridas. Dentre as causas congênitas, as malformações dos rins e do trato urinário assumem grande importância não só por sua elevada frequência, bem como por serem capazes de produzir DRC já nos primeiros meses de vida. ${ }^{53}$ As malformações dos rins e do trato urinário normalmente assumem maior gravidade quando associadas à obstrução do trato urinário, como ocorre nos casos de válvula de uretra posterior. ${ }^{23}$ Até recentemente, considerava-se que as nefropatias obstrutivas produziam lesão renal unicamente em decorrência dos efeitos mecânicos da obstrução ao fluxo de urina. ${ }^{54}$. No entanto, atualmente se sabe que as nefropatias obstrutivas podem lesar o tecido renal mesmo após alívio do processo obstrutivo, produzindo inflamação, fibrose intersticial e atrofia tubular. ${ }^{23,55}$. Em geral, as lesões permanentes se devem a apoptose tubular e fibrose renal. ${ }^{23}$. A apoptose de células tubulares renais e a fibrose são mediadas por citocinas tais como o TGF- $\beta 1$ e o TNF- $\alpha{ }^{56}$
Três processos são fundamentais para a lesão renal obstrutiva: a morte celular por apoptose e outras formas, a inflamação e a fibrose intersticial. ${ }^{23} \mathrm{O}$ estiramento mecânico dos túbulos dilatados por obstrução ao fluxo de urina promove apoptose ou transição epitélio-mesenquimal das células epiteliais tubulares e intersticiais. As células epiteliais lesadas produzem infrarregulação do fator de crescimento epidérmico e ativam o SRA..$^{55}$ Essas duas alterações estimulam a expressão do TGF- $\beta 1$ e a geração de espécies reativas de oxigênio, que, por sua vez, levam ao recrutamento de macrófagos intersticiais e à produção de MCP-1/CCL2, moléculas de adesão e TNF- $\alpha .{ }^{23}$ Esta sequência de eventos resulta em atrofia tubular e lesão de capilares peritubulares e glomérulos. ${ }^{23,55}$ Além disso, alterações fenotípicas transformam células epiteliais em miofibroblastos, que promovem fibrose intersticial através da expansão da matriz extracelular. ${ }^{23}$ O resultado final é a perda progressiva de todas as estruturas do néfron, conforme mostrado na Figura 1.

$\mathrm{O}$ aumento da produção tubular de TGF- $\beta 1$ contribui significativamente para a fibrose túbulo-intersticial por meio de ativação do fator nuclear de transcrição NF$\kappa \mathrm{B}$ e consequente deposição de matriz extracelular..$^{56} \mathrm{~A}$ atividade do NF-кB é também estimulada pela albumina, o que explica a correlação entre a proteinúria, inflamação túbulo-intersticial e fibrose renal. ${ }^{56} \mathrm{Em}$ modelo experimental de obstrução ureteral unilateral, a inibição da ECA ou o bloqueio do receptor AT1 atenuam a lesão renal, evidenciando o papel da Ang II na progressão da DRC nas nefropatias obstrutivas. ${ }^{57}$

Dessa forma, mesmo em malformações congênitas dos rins e do trato urinário, evidências clínicas e experimentais mostram que o processo inflamatório, mediado por citocinas e quimiocinas, também participa da instalação e da progressão das lesões renais.

\section{INFLAMAÇÃO NAS GLOMERULOPATIAS}

A relação entre glomerulopatia e inflamação já está tradicionalmente bem estabelecida na literatura..$^{10,17,22}$ Ressalta-se ainda que as doenças glomerulares determinam deterioração mais rápida da função renal quando comparadas a outras etiologias de DRC. ${ }^{58}$ A lesão glomerular pode ser deflagrada por diversos mecanismos imunológicos, tais como deposição de imunocomplexos circulantes no tecido renal, formação local de anticorpos com agressão direta a estruturas glomerulares, ativação local da cascata do complemento com liberação de mediadores inflamatórios e lesões mediadas por células (reações de hipersensibilidade tardia). ${ }^{59}$ Independentemente do mecanismo imunológico subjacente da lesão glomerular, ocorre, inicialmente, produção de mediadores 
inflamatórios como citocinas, quimiocinas, espécies reativas de oxigênio e lípides que promovem ativação de leucócitos, macrófagos e células intrínsecas do glomérulo renal. Posteriormente, há amplificação da resposta inflamatória por meio de influxo de linfócitos e macrófagos mediado pelo aumento da produção de citocinas e quimiocinas, oriundas tanto das células inflamatórias recrutadas quanto das células glomerulares intrínsecas. ${ }^{59}$ Paralelamente, ocorre ativação das células mesangiais que pode ser desencadeada pelo processo imunológico subjacente, bem como por estímulo de mediadores locais liberados pelas células inflamatórias e pelas células residentes. ${ }^{29} \mathrm{~A}$ ativação das células mesangiais determina a alteração fenotípica dessas células, que se transformam em fibroblastos capazes de liberar proteases, citocinas e mediadores oxidativos, ${ }^{29}$ tais como IL-1, MCP-1/ CCL2, RANTES/CCL5, fator de crescimento derivado de plaquetas, óxido nítrico, TGF- $\beta .{ }^{47}$ A liberação dessas citocinas pró-inflamatórias fibrogênicas pelos fibroblastos oriundos de células mesangiais que sofreram mudanças fenotípicas contribui para a glomeruloesclerose e a fibrose túbulo-intersticial. ${ }^{29,59} \mathrm{~A}$ lesão das células endoteliais glomerulares também promove glomeruloesclero$\mathrm{se}^{27}$ por meio de aumento da expressão de PAI-1, moléculas de adesão intracelular-1 (ICAM-1), IL-1, TNF- $\alpha$, IL-8/CXCL8 e MCP-1/CCL2. ${ }^{60}$ Dessa forma, a via final comum da DRC secundária às glomerulopatias também é caracterizada pela fibrose intersticial progressiva, lesão capilar peritubular por hipóxia e perda de funcionamento dos néfrons por esclerose glomerular e atrofia tubular (Figura 1). ${ }^{18}$

Existem evidências clínicas e experimentais que corroboram o papel das citocinas e quimiocinas na instalação e progressão da DRC nas doenças glomerulares. ${ }^{61,62} \mathrm{Em}$ modelo animal de glomerulopatia, Border et al. mostraram que a citocina fbrogênica TGF- $\beta 1$ estimula a proliferação celular mesangial e posterior instalação da fibrose. ${ }^{63}$ Vários estudos mostraram que o uso de antagonista de receptor de IL-1 melhora a lesão renal em modelo experimental de glomerulopatia crescêntica, sugerindo a participação da IL-1, uma citocina pró-inflamatória, na patogênese desta glomerulopatia. ${ }^{61,64,65}$

Em relação às evidências clínicas, Honkanen et al. mostraram excreção urinária elevada de TGF- $\beta 1$ em pacientes com glomerulopatia membranosa, a correlação positiva dos níveis desta citocina com índices morfológicos de cronicidade e sua diminuição após tratamento imunossupressor. ${ }^{66}$ Os achados desses autores sugerem que os efeitos fibrogênicos desta citocina contribuem para as alterações estruturais do tecido renal de pacientes com glomerulopatia membranosa. ${ }^{66}$ À semelhança dos achados em animais de experimentação, algumas citocinas pró-inflamatórias também já foram detectadas em tecido glomerular humano. ${ }^{62,67,68}$ Foram detectados aumentos dos RNAs mensageiros para o TNF- $\alpha$ e para a IL-1 na glomerulopatia crescêntica humana e maior expressão de TNF- $\alpha$ em células epiteliais tubulares de pacientes portadores de glomerulopatias proliferativas. ${ }^{62,67,68} \mathrm{Em}$ relação ao possível papel das quimiocinas no desencadeamento de alterações glomerulares iniciais, foi observada excreção urinária aumentada de IL-8/CXCL8 em pacientes portadores de doença glomerular primária. ${ }^{69,70}$ Esta elevação correlacionou-se à excreção urinária de proteínas em pacientes com síndrome nefrótica primária e mostrou-se reduzida durante a remissão da proteinúriae nos pacientes submetidos à pulsoterapia. ${ }^{69,70}$

\section{Citocinas e ouimiocinas como BIOMARCADORES DA DOENÇA RENAL CRÔNICA}

IL-1 - A família da IL-1 consiste em duas citocinas próinflamatórias, IL-1 $\alpha$ e IL-1 $\beta$ e um agente anti-inflamatório natural, o antagonista do receptor solúvel de IL-1 (IL-1Ra). A relação entre os níveis plasmáticos de IL-1 e IL-1Ra exerce papel significativo na susceptibilidade e gravidade de inúmeras doenças. Estudos mostram que esta relação prediz a evolução de doenças cardiovasculares, bem como o estabelecimento de glomerulopatias e mortalidade na DRC. ${ }^{71}$ A IL-1 é também considerada um mediador da fibrose túbulo-instersticial. ${ }^{71} \mathrm{O}$ aumento da expressão de IL-1 foi detectado em biópsias renais de pacientes com vasculite ${ }^{62}$ e no tecido renal remanescente de ratos submetidos à nefrectomia subtotal. ${ }^{47}$ Além disso, a administração de antagonistas de IL-1 inibiu a fibrose túbulo-intersticial em modelo animal de DRC. ${ }^{61}$

IL-6 - A IL-6 é uma citocina pró-inflamatória produzida por diversas células incluindo monócitos e células renais mesangiais. ${ }^{9,39}$ IL-6 induz a diferenciação de linfócitos B em células produtoras de anticorpos e a produção de proteínas de fase aguda como PCR e fibrinogênio. ${ }^{46}$ Além disso, esta citocina estimula a proliferação de células renais mesangiais e exerce papel fundamental na glomerulopatia proliferativa mesangial..$^{72}$ Alguns estudos têm sugerido a participação de IL-6 na fisiopatologia da nefrite lúpica, principalmente pela indução da produção de anticorpos nefritogênicos e pela proliferação mesangial. ${ }^{73}$ No entanto, Li et al., ao avaliarem uma coorte de pacientes com lúpus, não evidenciaram aumento significativo de IL-6 nos casos com nefrite ativa quando comparados aos pacientes sem nefrite. ${ }^{74}$

IL-8 - A primeira citocina quimioatraente a ser descoberta foi a IL-8/CXCL8, considerada, por 
isso, um marco na história da imunologia. ${ }^{6,26}$ A IL-8/ CXCL8 pertence à subfamília de quimiocinas CXC e exerce predominantemente efeito quimioatraente para neutrófilos. ${ }^{6,26}$ A excreção urinária de $\beta_{2}$ microglobulina, IL-6 e IL-8/CXCL8 relaciona-se à atividade inflamatória renal na nefrite lúpica. ${ }^{69,75}$ Há evidência da elevação urinária de IL-8/CXCL8, em pacientes portadores de nefrite lúpica ou nefropatia por imunoglobulina A (IgA). ${ }^{69}$ Observou-se redução dos níveis urinários de IL-8/CXCL8 nos períodos de remissão da nefrite lúpica. ${ }^{69}$ Por outro lado, o estudo de Li et al. não confirmou este achado, pois, apesar de haver elevação dos níveis de IL-8/CXCL8 em pacientes com lúpus, não foi detectada diferença entre os casos com e sem comprometimento renal. ${ }^{74}$ Yokoyama et al. mostraram o envolvimento de IL-8/CXCL8 na fase aguda da nefropatia por IgA caracterizada pela proliferação endocapilar. ${ }^{76}$ No entanto, Huang et al. sugeriram a participação da IL-8/CXCL8 nas fases avançadas por IgA, ao mostrarem níveis urinários aumentados em comparação com estágios precoces da doença e controles sadios. ${ }^{77}$ Foi também detectado que a IL-8/CXCL8 urinária eleva-se em fases iniciais da nefropatia diabética. ${ }^{11}$ Existem ainda evidências clínicas e experimentais de que essa quimiocina influencie a permeabilidade glomerular. ${ }^{70,78}$ Garin verificou que a administração IL-8/CXCL8 produz proteinúria, em animais, possivelmente através do aumento da permeabilidade glomerular. ${ }^{78}$ Em pacientes pediátricos, Cho et al. detectaram níveis séricos e urinários aumentados de IL-8/CXCL8 em portadores de síndrome nefrótica por lesão mínima em recidiva. ${ }^{79}$ Similarmente, Souto et al. mostraram uma correlação positiva entre a excreção de IL-8/CXCL8 e de proteína na urina de crianças com síndrome nefrótica primária. ${ }^{70}$

$T N F-\alpha-O$ TNF- $\alpha$ é uma citocina pró-inflamatória cuja produção é estimulada pela Ang II e associa-se à fibrose intersticial pela diferenciação de miofibroblastos e ativação do NF-кB., ${ }^{9,39}$ Em modelo experimental de glomerulopatia crescêntica, tanto a deficiência genética de TNF- $\alpha$ quanto a inibição farmacológica dessa citocina atenuam o desenvolvimento das lesões glomerulares. ${ }^{80}$ Em crianças com síndrome nefrótica por lesões mínimas observou-se também aumento da excreção urinária de TNF- $\alpha{ }^{79}$

TGF- $\beta$ - Os TGF- $\beta$ pertencem à superfamília TGF- $\beta$ composta por três isoformas homólogas, TGF$\beta 1$, TGF- $\beta 2$ e TGF- $\beta 3$, que são codificadas por diferentes genes. O TGF- $\beta 1$ é a isoforma predominantemente expressa pelo sistema imunológico. ${ }^{39,81} \mathrm{Yu}$ et al. demonstraram efeitos fibrogênicos de todas as três isoformas do TGF- $\beta$ sobre as células renais, porém o
TGF- $\beta 1$ medeia os efeitos do TGF- $\beta 2$ e do TGF- $\beta 3 .{ }^{81}$ O TGF- $\beta 1$ é classicamente conhecido por sua contribuição à progressão da lesão renal através da expansão da matriz extracelular e fibrose tecidual. ${ }^{50} \mathrm{O}$ TGF- $\beta 1$ induz a produção de PAI-1, regula o crescimento e diferenciação celulares, promove a produção de matriz extracelular, ${ }^{18}$ além de interagir com vias de sinalização intracelular da Ang-II que estimulam a fibrose intersticial renal e progressão da DRC. ${ }^{19}$ Foram detectados aumentos da expressão e dos níveis séricos e urinários dessa citocina em pacientes com glomeruloesclerose focal e segmentar, ${ }^{82-84}$ nefropatia diabética ${ }^{85}$ e em pacientes pediátricos com malformações congênitas do trato urinária associadas à redução da função renal à cintilografia estática. ${ }^{86} \mathrm{O}$ efeito benéfico de anticorpos anti-TGF- $\beta 1$ em modelos de uropatia obstrutiva e glomerulopatias corroboram o papel do TGF- $\beta 1$ na progressão da DRC. ${ }^{63}$

MCP-1 - O MCP-1/CCL2 é uma quimiocina da família CC, que recruta células da linhagem monócitos-macrófagos, estimula a liberação de histamina pelos basófilos e atua tanto nas fases iniciais, quanto na progressão da lesão túbulo-intersticial renal. ${ }^{26,87} \mathrm{O}$ MCP-1/CCL2 induz fibrose túbulo-intersticial através do recrutamento e ativação de macrófagos que liberam, então, TGF- $\beta 1$. Recentemente, foram demonstradas as significativas correlações entre o número de fibroblastos intersticiais, o número de macrófagos também intersticiais e a excreção urinária de MCP-1/CCL2 na DRC. ${ }^{87}$ Existem inúmeras evidências do papel desta quimiocina na DRC de diversas etiologias. ${ }^{88-90}$

Em ratos com obstrução ureteral unilateral, a excreção urinária de MCP-1/CCL2 está aumentada e correlaciona-se ao grau de obstrução. ${ }^{88} \mathrm{~A}$ presença de deposição de colágeno dos tipos III e IV na região mesangial e a infiltração intersticial de monócitos/macrófagos em modelo experimental de uropatia obstrutiva indicam o papel de MCP-1/CCL2 em sua fisiopatologia. ${ }^{57}$

Estudos também corroboram a ação da quimiocina MCP-1/CCL2, induzida por TGF- $\beta$, na deposição de matriz extracelular e na proteinúria de pacientes portadores de alterações glomerulares, tais como a síndrome nefrótica córtico-resistente e a nefropatia diabética. . $^{11,51,52}$ No fluido inicial coletado do túbulo proximal de ratos diabéticos, observou-se aumento da liberação de MCP-1/ CCL2 que foi bloqueado por anticorpos anti-TGF- $\beta .{ }^{92}$ Postula-se que a albuminúria ativa a expressão tubular de quimiocinas no túbulo proximal através de mecanismo dependente de NF-кB. ${ }^{93,94}$ Wang et al. também sugeriram papel da albuminúria após evidenciarem produção de MCP-1/CCL2 por células tubulares. ${ }^{94}$ Alguns estudos têm indicado que o bloqueio do MCP-1/CCL2 
atenua a nefrite intersticial, a lesão tubular e a fibrose induzidas pela proteinúria. ${ }^{95}$ Além disso, animais com ablação genética do receptor CCR2 para MCP-1/CCL2 apresentaram menor elevação dos níveis pressóricos e menos lesão renal induzidas pela infusão de Ang II. ${ }^{96}$ Níveis urinários de MCP-1/CCL2 estão aumentados em diabéticos tipo 2 quando comparados à população geral, e este aumento mostrou-se progressivo considerando-se os estágios de nefropatia. ${ }^{11} \mathrm{Nas}$ doenças glomerulares, houve redução de macrófagos e dos os níveis urinários de MCP-1/CCL2 durante a fase de remissão induzida por corticóide. ${ }^{87} \mathrm{O} \mathrm{MCP}-1 / \mathrm{CCL} 2$ mostrou-se também elevado na fase crônica da nefropatia por IgA na qual ocorre proliferação mesangial e infiltração celular intersticial. ${ }^{76}$

Em relação às doenças autoimunes, a deficiência de MCP-1/CCL2 e de seu receptor atenua a manifestação de doença em modelos animais. ${ }^{97} \mathrm{Tal}$ achado é corroborado pelos estudos realizados em pacientes com nefrite lúpica. ${ }^{98-100}$ Os níveis urinários de MCP-1/CCL2 em pacientes com nefrite lúpica encontravam-se marcadamente elevados e relacionados com sua expressão intrarrenal. ${ }^{98-100} \mathrm{O}$ artigo de revisão de Li et al. sugere que o MCP-1/CCL2 urinário possa ser considerado um biomarcador da nefrite lúpica por apresentar-se significativamente elevado nos pacientes com acometimento renal. ${ }^{74}$ Nesse contexto, Rovin et al. sugerem que o MCP-1/CCL2 urinário possa ser um biomarcador em pacientes com lúpus, independentemente da presença de comprometimento renal e do uso de imunossupressão. ${ }^{89}$

As Tabelas 1 e 2 resumem os resultados obtidos em estudos experimentais e clínicos que dosaram citocinas e quimiocinas em doenças renais.

\section{Tabela 1 RESUMO DOS PRINCIPAIS ESTUDOS EXPERIMENTAIS SOBRE CITOCINAS E OUIMIOCINAS NA DOENÇA RENAL CRÔNICA}

\begin{tabular}{|c|c|c|c|}
\hline Autor & Modelo & Citocina & Resultado principal \\
\hline Lan et al. ${ }^{64}$ & Animal & IL-1 & $\begin{array}{l}\text { Antagonista de receptor de IL-1 inibiu a formação de crescentes } \\
\text { glomerulares }\end{array}$ \\
\hline Tang et al. ${ }^{65}$ & Animal & IL-1 & $\begin{array}{l}\text { Antagonista de receptor de IL-1 promoveu melhora da glomerulonefrite } \\
\text { anti-membrana basal glomerular }\end{array}$ \\
\hline Wang et al. ${ }^{94}$ & In vitro & MCP-1 & $\begin{array}{l}\text { Presença de proteinúria estimulou a produção de MCP-1 por células } \\
\text { tubulares }\end{array}$ \\
\hline Tesch et al. ${ }^{68}$ & In vitro & IL-1 & $\begin{array}{l}\text { Células renais intrínsecas foram a principal fonte de IL-1 em rins } \\
\text { normais e rins com glomerulonefrite }\end{array}$ \\
\hline Border et al. ${ }^{63}$ & Animal & TGF- $\beta 1$ & Anticorpo contra o TGF- $\beta 1$ suprime a glomerulonefrite experimental \\
\hline Lan et al. ${ }^{61}$ & Animal & IL-1 & $\begin{array}{l}\text { Antagonista de receptor de IL-1 inibe a progressão de glomerulonefrite } \\
\text { crescêntica }\end{array}$ \\
\hline Hisada et al. ${ }^{48}$ & Animal & MCP-1 & $\begin{array}{l}\text { Camundongos com ablação genética do receptor AT1 da Ang II } \\
\text { possuem menor expressão de MCP-1 }\end{array}$ \\
\hline Kato et al. ${ }^{49}$ & Animal & MCP-1 & $\begin{array}{l}\text { Bloqueio do SRA com iECA ou com BRA reduz a expressão de MCP-1 } \\
\text { em modelo animal de diabetes mellitus }\end{array}$ \\
\hline Taal et al. ${ }^{47}$ & Animal & $\begin{array}{l}\text { MCP-1, TGF- } \\
\beta 1, I L-1, \text { TNF- } \alpha\end{array}$ & $\begin{array}{l}\text { Aumento do RNA mensageiro para MCP- } 1 \text {, IL-1, TGF- } \beta 1 \text { e TNF- } \alpha \text { no rim } \\
\text { remanescente de animais submetidos à nefrectomia subtotal }\end{array}$ \\
\hline $\begin{array}{l}\text { Donadelli et } \\
\text { al. }{ }^{93}\end{array}$ & Animal & MCP-1/NF-kB & Proteinúria estimula a lesão renal dependente de MCP-1 e NF-kB \\
\hline $\begin{array}{l}\text { Wang e } \\
\text { Hirschberg }\end{array}$ & In vitro & TGF- $\beta 1$ & $\begin{array}{l}\text { TGF- } \beta 1 \text { ultrafiltrado contribui para fibrose intersticial na nefropatia } \\
\text { diabética experimental }\end{array}$ \\
\hline $\begin{array}{l}\text { Stephan et } \\
\text { al. }{ }^{88}\end{array}$ & Animal & MCP-1 & $\begin{array}{l}\text { Níveis urinários e expressão do RNA mensageiro para MCP-1 como } \\
\text { indicadores do grau de atrofia na obstrução ureteral parcial }\end{array}$ \\
\hline Qi et al. ${ }^{91}$ & In vitro & $\begin{array}{l}\text { TGF- } \beta 1 \\
\text { MCP-1, IL-8 }\end{array}$ & $\begin{array}{l}\text { TGF- } \beta 1 \text { induz a produção de MCP-1 e IL-8 em células de túbulo renal } \\
\text { proximal }\end{array}$ \\
\hline Liao et al. ${ }^{96}$ & Animal & MCP-1 & $\begin{array}{l}\text { Animais com ablação genética do receptor CCR2 para MCP-1 } \\
\text { apresentaram menos hipertensão e lesão renal induzida por Ang II }\end{array}$ \\
\hline Knight et al. ${ }^{43}$ & Animal & MCP-1 & $\begin{array}{l}\text { Tratamento com o antioxidante tempol reduziu os níveis urinários de } \\
\text { MCP-1 em modelo animal de obesidade e hipertensão }\end{array}$ \\
\hline
\end{tabular}

Ang II - angiotensina II; iECA - inibidor da enzima conversora de angiotensina; SRA - sistema renina angiotensina; BRA - bloqueador de receptor AT1 da angiotensina II 


\section{Tabela 2 RESUMO DOS PRINCIPAIS ESTUDOS CLÍNICOS SOBRE CITOCINAS E QUIMIOCINAS NA DOENÇA RENAL CRÔNICA}

\begin{tabular}{|c|c|c|c|c|c|}
\hline Autor & Ref & $\mathrm{n}$ & $\begin{array}{l}\text { Faixa } \\
\text { etária } \\
\text { (anos) }\end{array}$ & Citocina & Resultado principal \\
\hline Noronha et al. ${ }^{62}$ & 62 & 22 & $10-74$ & TNF- $\alpha / I L-1$ & $\begin{array}{l}\text { Produção no tecido renal de TNF- } \alpha \text { e IL-1 em pacientes com } \\
\text { glomerulopatia ANCA-positiva }\end{array}$ \\
\hline Wada et al. ${ }^{69}$ & 69 & 96 & $4-82$ & IL-8 & $\begin{array}{l}\text { Aumento da excreção urinária de IL-8 e de sua imuno- } \\
\text { histoquímica renal na doença glomerular ativa }\end{array}$ \\
\hline Norris et al. ${ }^{100}$ & 100 & 48 & Adultos & MCP-1 & $\begin{array}{l}\text { Aumento da excreção urinária de MCP-1 em pacientes com } \\
\text { nefrite lúpica }\end{array}$ \\
\hline Yamamoto et al. ${ }^{83}$ & 83 & 53 & Adultos & $\begin{array}{l}\text { TGF- } \beta 1 / \\
\text { PAI-1 }\end{array}$ & $\begin{array}{l}\text { Aumento da expressão renal do TGF- } \beta 1 \text { e do PAl-1 em } \\
\text { glomerulopatias humanas }\end{array}$ \\
\hline Wada et al. ${ }^{98}$ & 98 & 42 & Adultos & MCP-1 & $\begin{array}{l}\text { Correlação entre os níveis urinários de MCP-1 e a atividade da } \\
\text { nefrite lúpica }\end{array}$ \\
\hline Honkanen et al. ${ }^{66}$ & 66 & 64 & $25-69$ & TGF- $\beta 1$ & $\begin{array}{l}\text { Aumento da expressão do RNA mensageiro para o TGF- } \beta 1 \text { na } \\
\text { glomerulopatia membranosa humana }\end{array}$ \\
\hline Rivarola et al. ${ }^{85}$ & 85 & 23 & $19-57$ & TGF- $\beta 1$ & $\begin{array}{l}\text { Relação entre a atividade do TGF- } \beta 1 \text { na urina de pacientes } \\
\text { com diabetes tipo } 2 \text { e nefropatia diabética }\end{array}$ \\
\hline Yokoyama et al. ${ }^{76}$ & 76 & 49 & $16-70$ & $\begin{array}{l}\text { MCP-1/ } \\
\text { IL-8 }\end{array}$ & $\begin{array}{l}\text { Aumento dos níveis urinários de MCP-1 e IL-8 de acordo com } \\
\text { a atividade e as fases da nefropatia por lgA }\end{array}$ \\
\hline Tsai et al. ${ }^{75}$ & 75 & 27 & Adultos & IL-6/IL-8 & $\begin{array}{l}\text { Aumento da excreção urinária de IL-6 e IL-8 em pacientes com } \\
\text { nefrite lúpica em atividade }\end{array}$ \\
\hline Huang et al. ${ }^{77}$ & 77 & 27 & $19-55$ & IL-8 & $\begin{array}{l}\text { Associação entre o aumento dos níveis urinários de IL-8 e a } \\
\text { atividade da nefropatia por lgA }\end{array}$ \\
\hline Tashiro et al. ${ }^{11}$ & 11 & 24 & Adultos & $\begin{array}{l}\text { MCP-1/ } \\
\text { IL-8 }\end{array}$ & $\begin{array}{l}\text { Aumento dos níveis urinários de MCP-1 e IL-8 em pacientes } \\
\text { com nefropatia diabética }\end{array}$ \\
\hline Goumenos et al. ${ }^{82}$ & 82 & 25 & $51 \pm 16$ & TGF- $\beta 1$ & $\begin{array}{l}\text { Aumento da expressão do TGF- } \beta 1 \text { no tecido renal de } \\
\text { pacientes com doença glomerular e proteinúria }\end{array}$ \\
\hline Strehlau et al. ${ }^{84}$ & 84 & 53 & Crianças & TGF- $\beta 1$ & $\begin{array}{l}\text { Aumento da transcrição renal do TGF- } \beta 1 \text { em crianças com } \\
\text { glomerulosclerose focal e segmentar }\end{array}$ \\
\hline Panichi et al. ${ }^{37}$ & 37 & 103 & $50 \pm 6,3$ & IL-6 & $\begin{array}{l}\text { Relação entre níveis elevados de IL-6 e redução da função } \\
\text { renal na DRC pré-dialítica }\end{array}$ \\
\hline $\begin{array}{l}\text { Amann, Tinzmann } \\
\text { e Angelkort }{ }^{51}\end{array}$ & 51 & 22 & $62,4 \pm 10,9$ & МСР-1 & $\begin{array}{l}\text { Melhora da nefropatia diabética com uso de iECA em } \\
\text { decorrência de inibição de MCP-1 no tecido renal }\end{array}$ \\
\hline Agarwal 52 & 52 & 16 & $53 \pm 9$ & MCP-1 & $\begin{array}{l}\text { Efeito renoprotetor dos BRA na nefropatia diabética por meio } \\
\text { de redução dos níveis urinários de MCP-1 }\end{array}$ \\
\hline $\begin{array}{l}\text { August e } \\
\text { Suthanthiran }{ }^{50}\end{array}$ & 50 & 98 & Adultos & TGF- $\beta 1$ & $\begin{array}{l}\text { Detecção de níveis urinários mais elevados de TGF- } \beta 1 \text { em } \\
\text { pacientes afro-americanos com DRC terminal comparados } \\
\text { aos pacientes brancos também com DRC terminal }\end{array}$ \\
\hline Cho et al. ${ }^{79}$ & 79 & 19 & $2-15$ & IL-8/TNF- $\alpha$ & $\begin{array}{l}\text { Aumento dos níveis urinários de IL-8 e TNF- } \alpha \text { na síndrome } \\
\text { nefrótica por lesões mínimas }\end{array}$ \\
\hline Tucci et al. ${ }^{99}$ & 99 & 134 & Adultos & MCP-1 & $\begin{array}{l}\text { Associação de polimorfismo funcional em promotor do gene } \\
\text { do MCP-1 com a nefrite lúpica }\end{array}$ \\
\hline Rovin et al. 89 & 89 & 33 & Adultos & $\begin{array}{l}\text { MCP-1/ } \\
\quad \text { IL-8 }\end{array}$ & $\begin{array}{l}\text { Aumento dos níveis urinários de MCP-1 e IL-8 na nefrite lúpica } \\
\text { em atividade }\end{array}$ \\
\hline Grenda et al. ${ }^{38}$ & 38 & 303 & $11,5 \pm 3,9$ & TGF- $\beta 1$ & Aumento da excreção urinária de TGF- $\beta 1$ na DRC estágios II-IV \\
\hline Eardley et al. ${ }^{87}$ & 87 & 110 & $20-87$ & MCP-1 & $\begin{array}{l}\text { Correlação entre níveis urinários de MCP-1 e relação } \\
\text { proteína:creatinina e piora da função renal na DRC }\end{array}$ \\
\hline Souto et al. ${ }^{70}$ & 70 & 32 & Crianças & $\begin{array}{l}\text { TGF- } \beta 1 / \\
\text { IL-8 }\end{array}$ & $\begin{array}{l}\text { Correlação entre os níveis urinários de IL-8 e a proteinúria de } \\
24 \text { h em crianças com síndrome nefrótica primária }\end{array}$ \\
\hline $\begin{array}{l}\text { Choudhary e } \\
\text { Ahlawat }^{36}\end{array}$ & 36 & 60 & Adultos & IL-6 & $\begin{array}{l}\text { Níveis circulantes de IL-6 se correlacionaram com proteinúria, } \\
\text { com os níveis de proteína C reativa e com o descontrole } \\
\text { glicêmico na nefropatia diabética }\end{array}$ \\
\hline Stangou et al..$^{90}$ & 90 & 33 & $18-65$ & $\begin{array}{l}\text { MCP-1/ } \\
\text { IL-6 }\end{array}$ & $\begin{array}{l}\text { Níveis urinários de MCP-1 e IL-6 foram preditores da evolução } \\
\text { na nefropatia por IgA }\end{array}$ \\
\hline Vasconcelos et al. ${ }^{86}$ & 86 & 100 & Crianças & $\begin{array}{l}\text { TGF- } \beta 1 / \\
\text { IL-6/TNF- } \alpha\end{array}$ & $\begin{array}{l}\text { Aumento do TGF- } \beta 1 \text { urinário em crianças com malformações } \\
\text { congênitas do trato urinário com captação renal reduzida na } \\
\text { cintilografia renal estática }\end{array}$ \\
\hline
\end{tabular}

DRC - doença renal crônica; IgA - imunoglobulina A; PAI-1 - inibidor da ativação do plasminogênio-1; BRA - bloqueador de receptor AT1 da angiotensina, $\mathrm{n}$ - número de casos estudados 


\section{Conclusão}

A descoberta de novas abordagens diagnósticas e terapêuticas alternativas para a DRC cada vez mais se impõem. Nesse contexto, a pesquisa de biomarcadores tem assumido grande importância. Diante das evidências clínicas e experimentais, é incontestável o papel da inflamação na DRC. Dessa forma, é fundamental o entendimento dos efeitos de quimiocinas e citocinas na instalação e progressão da lesão renal, tendo em vista a possibilidade de definir novos marcadores prognósticos e, talvez até, alvos terapêuticos alternativos e mais eficientes. No entanto, apesar de grande avanço no conhecimento dos mecanismos fisiopatológicos que relacionam a resposta imunoinflamatória à $\mathrm{DRC}$, muitos aspectos ainda precisam ser elucidados.

\section{REFERÊNCIAS}

1. Stenvinkel P. Chronic kidney disease: a public health priority and harbinger of premature cardiovascular disease. J Intern Med 2010;268:456-67.

2. Hunley TE, Ma LJ, Kon V. Scope and mechanisms of obesity-related renal disease. Curr Opin Nephrol Hypertens 2010;19:227-34.

3. Meguid El Nahas A, Bello AK. Chronic kidney disease: the global challenge. Lancet 2005;365:331-40.

4. Sesso RCC, Lopes AA, Thomé FS, Bevilacqua JL, Romão Junior JER, Lugon J. Resultados do Censo de Diálise da SBN, 2007. J Bras Nefrol 2007;29:197-202.

5. Sesso RCC, Lopes AA, Thomé FS, Lugon JR, Burdmann EA. Censo Brasileiro de Diálise, 2009. J Bras Nefrol 2010;32:374-8.

6. Gerard C, Rollins BJ. Chemokines and disease. Nat Immunol 2001;2:108-15.

7. Suliman ME, Stenvinkel P. Contribution of inflammation to vascular disease in chronic kidney disease patients. Saudi J Kidney Dis Transpl 2008;19:329-45.

8. Tracey KJ. The inflammatory reflex. Nature 2002;420:853-9.

9. Stenvinkel P, Ketteler M, Johnson RJ, Lindholm B, Pecoits-Filho R, Riella M, et al. IL-10, IL-6, and TNFalpha: central factors in the altered cytokine network of uremia - the good, the bad, and the ugly. Kidney Int 2005;67:1216-33.

10. Oberg BP, McMenamin E, Lucas FL, McMonagle E, Morrow J, Ikizler TA, et al. Increased prevalence of oxidant stress and inflammation in patients with moderate to severe chronic kidney disease. Kidney Int 2004;65:1009-16.

11. Tashiro K, Koyanagi I, Saitoh A, Shimizu A, Shike $\mathrm{T}$, Ishiguro $\mathrm{C}$, et al. Urinary levels of monocyte chemoattractant protein-1 (MCP-1) and interleukin-8 (IL-8), and renal injuries in patients with type 2 diabetic nephropathy. J Clin Lab Anal 2002;16:1-4.

12. Pecoits-Filho R, Lindholm B, Stenvinkel P. The malnutrition, inflammation, and atherosclerosis (MIA) syndrome - the heart of the matter. Nephrol Dial Transplant 2002;17:28-31.
13. Zimmermann J, Herrlinger S, Pruy A, Metzger T, Wanner C. Inflammation enhances cardiovascular risk and mortality in hemodialysis patients. Kidney Int 1999;55:648-58.

14. Nascimento MM, Pecoits-Filho R, Lindholm B, Riella MC, Stenvinkel P. Inflammation, malnutrition and atherosclerosis in end-stage renal disease: a global perspective. Blood Purif 2002;20:454-8.

15. Stenvinkel P, Carrero JJ, Axelsson J, Lindholm B, Heimbürger O, Massy Z. Emerging biomarkers for evaluating cardiovascular risk in the chronic kidney disease patient: how do new pieces fit into the uremic puzzle? Clin J Am Soc Nephrol 2008;3:505-21.

16. Cheung AK, Sarnak MJ, Yan G, Dwyer JT, Heyka RJ, Rocco MV, et al. Atherosclerotic cardiovascular disease risks in chronic hemodialysis patients. Kidney Int 2000;58:353-62.

17. Cheung WW, Paik KH, Mak RH. Inflammation and cachexia in chronic kidney disease. Pediatr Nephrol 2010;25:711-24.

18. Eddy AA. Progression in chronic kidney disease. Adv Chronic Kidney Dis 2005;12:353-65.

19. Ruiz-Ortega M, Lorenzo O, Suzuki Y, Rupérez M, Egido J. Proinflammatory actions of angiotensins. Curr Opin Nephrol Hypertens 2001;10:321-9.

20. Moss RB, Moll T, El-Kalay M, Kohne C, Soo Hoo W, Encinas J, et al. Th1/Th2 cells in inflammatory disease states: therapeutic implications. Expert Opin Biol Ther 2004;4:1887-96.

21. El Nahas M. The global challenge of chronic kidney disease. Kidney Int 2005;68:2918-29.

22. Pecoits-Filho R, Sylvestre LC, Stenvinkel P. Chronic kidney disease and inflammation in pediatric patients: from bench to playground. Pediatr Nephrol 2005;20:714-20.

23. Chevalier RL, Thornhill BA, Forbes MS, Kiley SC. Mechanisms of renal injury and progression of renal disease in congenital obstructive nephropathy. Pediatr Nephrol 2010;25:687-97.

24. Rao M, Wong C, Kanetsky P, Girndt M, Stenvinkel P, Reilly M, et al. Cytokine gene polymorphism and progression of renal and cardiovascular diseases. Kidney Int 2007;72:549-56.

25. Krane V, Wanner C. Statins, inflammation and kidney disease. Nat Rev Nephrol 2011; 7:385-97.

26. Mackay CR. Chemokines: immunology's high impact factors. Nat Immunol 2001;2:95-101.

27. Lee LK, Meyer TW, Pollock AS, Lovett DH. Endothelial cell injury initiates glomerular sclerosis in the rat remnant kidney. J Clin Invest 1995;96:953-64.

28. Liu Y. Renal fibrosis: new insights into the pathogenesis and therapeutics. Kidney Int 2006;69:213-7.

29. Couser WG. Pathogenesis of glomerular damage in glomerulonephritis. Nephrol Dial Transplant 1998;13:10-5

30. Streetz KL, Wustefeld T, Klein C, Manns MP, Trautwein C. Mediators of inflammation and acute phase response in the liver. Cell Mol Biol (Noisy-legrand) 2001;47:661-73.

31. Klahr S, Morrissey J. Progression of chronic renal disease. Am J Kidney Dis 2003;41:S3-7.

32. Menon V, Greene T, Wang X, Pereira AA, Marcovina SM, Beck GJ, et al. C-reactive protein and albumin as 
predictors of all-cause and cardiovascular mortality in chronic kidney disease. Kidney Int 2005;68:76672.

33. Knight EL, Rimm EB, Pai JK, Rexrode KM, Cannuscio CC, Manson JE, et al. Kidney dysfunction, inflammation, and coronary events: a prospective study. J Am Soc Nephrol 2004;15:1897-903.

34. Srivaths PR, Silverstein DM, Leung J, Krishnamurthy R, Goldstein SL. Malnutrition-inflammation-coronary calcification in pediatric patients receiving chronic hemodialysis. Hemodial Int 2010;14:263-9.

35. Hasuike Y, Nonoguchi H, Ito K, Naka M, Kitamura $\mathrm{R}$, Nanami $\mathrm{M}$, et al. Interleukin-6 is a predictor of mortality in stable hemodialysis patients. Am J Nephrol 2009;30:389-98.

36. Choudhary N, Ahlawat RS. Interleukin-6 and C-reactive protein in pathogenesis of diabetic nephropathy: new evidence linking inflammation, glycemic control, and microalbuminuria. Iran J Kidney Dis 2008;2:72-9.

37. Panichi V, Migliori M, De Pietro S, Taccola D, Bianchi AM, Giovannini L, et al. C-reactive protein and interleukin-6 levels are related to renal function in predialytic chronic renal failure. Nephron 2002;91:594600.

38. Grenda R, Wühl E, Litwin M, Janas R, Sladowska J, Arbeiter $\mathrm{K}$, et al. Urinary excretion of endothelin-1 (ET-1), transforming growth factor- beta1 (TGF-beta1) and vascular endothelial growth factor (VEGF165) in paediatric chronic kidney diseases: results of the ESCAPE trial. Nephrol Dial Transplant 2007;22:348794.

39. Abbas AK, Lichtman AH. Cellular and Molecular Immunology. 5th ed. Philadelphia: Saunders, Elsevier Science; 2003. p. 243-74: Cytokines.

40. Kramer H, Luke A, Bidani A, Cao G, Cooper R, McGee D. Obesity and prevalent and incident CKD: the Hypertension Detection and Follow-Up Program. Am J Kidney Dis 2005;46:587-94.

41. Eddy AA, Fogo AB. Plasminogen activator inhibitor-1 in chronic kidney disease: evidence and mechanisms of action. J Am Soc Nephrol 2006;17:2999-3012.

42. Ceriello A, Motz E. Is oxidative stress the pathogenic mechanism underlying insulin resistance, diabetes, and cardiovascular disease? The common soil hypothesis revisited. Arterioscler Thromb Vasc Biol 2004;24:81623.

43. Knight SF, Yuan J, Roy S, Imig JD. Simvastatin and tempol protect against endothelial dysfunction and renal injury in a model of obesity and hypertension. Am J Physiol Renal Physiol 2010;298:F86-94.

44. Wong C, Kanetsky P, Raj D. Genetic polymorphisms of the RAS-cytokine pathway and chronic kidney disease. Pediatr Nephrol 2008;23:1037-51.

45. National Center for Biotechnology Information SNP database [database on the Internet]. [cited 2011 Aug 26]. Available from: http://www.ncbi.nlm.nih.gov/ projects/SNP.

46. Yvan-Charvet L, Massiéra F, Lamandé N, Ailhaud G, Teboul M, Moustaid-Moussa N, et al. Deficiency of angiotensin type 2 receptor rescues obesity but not hypertension induced by overexpression of angiotensinogen in adipose tissue. Endocrinology 2009;150:1421-8.
47. Taal MW, Zandi-Nejad K, Weening B, Shahsafaei A, Kato S, Lee KW, et al. Proinflammatory gene expression and macrophage recruitment in the rat remnant kidney. Kidney Int 2000;58:1664-76.

48. Hisada Y, Sugaya T, Yamanouchi M, Uchida H, Fujimura H, Sakurai H, et al. Angiotensin II plays a pathogenic role in immune-mediated renal injury in mice. J Clin Invest 1999;103:627-35.

49. Kato S, Luyckx VA, Ots M, Lee KW, Ziai F, Troy $\mathrm{JL}$, et al. Renin-angiotensin blockade lowers MCP-1 expression in diabetic rats. Kidney Int 1999;56:103748.

50. August P, Suthanthiran M. Transforming growth factor beta and progression of renal disease. Kidney Int Suppl 2003;87:S99-104.

51. Amann B, Tinzmann R, Angelkort B. ACE inhibitors improve diabetic nephropathy through suppression of renal MCP-1. Diabetes Care 2003;26:2421-5.

52. Agarwal R. Proinflammatory effects of oxidative stress in chronic kidney disease: role of additional angiotensin II blockade. Am J Physiol Renal Physiol 2003;284:F863-9.

53. Warady BA, Chadha V. Chronic kidney disease in children: the global perspective. Pediatr Nephrol 2007;22:1999-2009.

54. Rohatgi R, Flores D. Intratubular hydrodynamic forces influence tubulointerstitial fibrosis in the kidney. Curr Opin Nephrol Hypertens 2010;19:65-71.

55. Truong LD, Gaber L, Eknoyan G. Obstructive uropathy. Contrib Nephrol 2011;169:311-26.

56. Takase O, Marumo T, Imai N, Hirahashi J, Takayanagi A, Hishikawa K, et al. NF-kappaB-dependent increase in intrarenal angiotensin II induced by proteinuria. Kidney Int 2005;68:464-73.

57. Satoh M, Kashihara N, Yamasaki Y, Maruyama K, Okamoto K, Maeshima Y, et al. Renal interstitial fibrosis is reduced in angiotensin II type 1a receptordeficient mice. J Am Soc Nephrol 2001;12:317-25.

58. Soares CM, Diniz JS, Lima EM, Oliveira GR, Canhestro MR, Colosimo EA, et al. Predictive factors of progression to chronic kidney disease stage 5 in a predialysis interdisciplinary programme. Nephrol Dial Transplant 2009;24:848-55.

59. Harris RC, Neilson EG. Toward a unified theory of renal progression. Annu Rev Med 2006;57:365-80.

60. Vielhauer V, Eis V, Schlondorff D, Anders HJ. Identifying chemokines as therapeutic targets in renal disease: lessons from antagonist studies and knockout mice. Kidney Blood Press Res 2004;27:226-38.

61. Lan HY, Nikolic-Paterson DJ, Mu W, Vannice JL, Atkins RC. Interleukin-1 receptor antagonist halts the progression of established crescentic glomerulonephritis in the rat. Kidney Int 1995;47:1303-9.

62. Noronha IL, Krüger C, Andrassy K, Ritz E, Waldherr R. In situ production of TNF-alpha, IL-1 beta and IL$2 \mathrm{R}$ in ANCA-positive glomerulonephritis. Kidney Int 1993;43:682-92.

63. Border WA, Okuda S,LanguinoLR,Sporn MB, Ruoslahti E. Suppression of experimental glomerulonephritis by antiserum against transforming growth factor beta 1 . Nature 1990;346:371-4.

64. Lan HY, Nikolic-Paterson DJ, Zarama M, Vannice JL, Atkins RC. Suppression of experimental crescentic 
glomerulonephritis by the interleukin-1 receptor antagonist. Kidney Int 1993;43:479-85.

65. Tang WW, Feng L, Vannice JL, Wilson CB. Interleukin-1 receptor antagonist ameliorates experimental antiglomerular basement membrane antibody-associated glomerulonephritis. J Clin Invest 1994;93:273-9.

66. Honkanen E, Teppo AM, Törnroth T, Groop PH, Grönhagen-Riska C. Urinary transforming growth factor-beta 1 in membranous glomerulonephritis. Nephrol Dial Transplant 1997;12:2562-8.

67. Takemura T, Yoshioka K, Murakami K, Akano N, Okada M, Aya N, et al. Cellular localization of inflammatory cytokines in human glomerulonephritis. Virchows Arch 1994;424:459-64.

68. Tesch GH, Yang N, Yu H, Lan HY, Foti R, Chadban SJ, et al. Intrinsic renal cells are the major source of interleukin-1 beta synthesis in normal and diseased rat kidney. Nephrol Dial Transplant 1997;12:1109-15.

69. Wada T, Yokoyama H, Tomosugi N, Hisada Y, Ohta S, Naito T, et al. Detection of urinary interleukin-8 in glomerular diseases. Kidney Int 1994;46:455-60.

70. Souto MF, Teixeira AL, Russo RC, Penido MG, Silveira KD, Teixeira MM, et al. Immune mediators in idiopathic nephrotic syndrome: evidence for a relation between interleukin 8 and proteinuria. Pediatr Res 2008;64:637-42.

71. Arend WP. The balance between IL-1 and IL-1Ra in disease. Cytokine Growth Factor Rev 2002;13:323-40.

72. Horii Y, Iwano M, Hirata E, Shiiki M, Fujii Y, Dohi $\mathrm{K}$, et al. Role of interleukin- 6 in the progression of mesangial proliferative glomerulonephritis. Kidney Int Suppl 1993;39(Suppl):S71-5.

73. Iwano M, Dohi K, Hirata E, Kurumatani N, Horii Y, Shiiki H, et al. Urinary levels of IL-6 in patients with active lupus nephritis. Clin Nephrol 1993;40:16-21.

74. Li Y, Tucci M, Narain S, Barnes EV, Sobel ES, Segal MS, et al. Urinary biomarkers in lupus nephritis. Autoimmun Rev 2006;5:383-8.

75. Tsai CY, Wu TH, Yu CL, Lu JY, Tsai YY. Increased excretions of beta2-microglobulin, IL-6, and IL-8 and decreased excretion of Tamm-Horsfall glycoprotein in urine of patients with active lupus nephritis. Nephron 2000;85:207-14.

76. Yokoyama H, Wada T, Furuichi K, Segawa C, Shimizu M, Kobayashi K, et al. Urinary levels of chemokines (MCAF/MCP-1, IL-8) reflect distinct disease activities and phases of human IgA nephropathy. J Leukoc Biol 1998;63:493-9.

77. Huang F, Horikoshi S, Kurusu A, Shibata T, Suzuki S, Funabiki K, et al. Urinary levels of interleukin-8 (IL-8) and disease activity in patients with IgA nephropathy. J Clin Lab Anal 2001;15:30-4.

78. Garin EH. Circulating mediators of proteinuria in idiopathic minimal lesion nephrotic syndrome. Pediatr Nephrol 2000;14:872-8.

79. Cho MH, Lee HS, Choe BH, Kwon SH, Chung KY, Koo $\mathrm{JH}$, et al. Interleukin-8 and tumor necrosis factor-alpha are increased in minimal change disease but do not alter albumin permeability. Am J Nephrol 2003;23:260-6.

80. Karkar AM, Smith J, Pusey CD. Prevention and treatment of experimental crescentic glomerulonephritis by blocking tumour necrosis factor-alpha. Nephrol Dial Transplant 2001;16:518-24.
81. Yu L, Border WA, Huang Y, Noble NA. TGF-beta isoforms in renal fibrogenesis. Kidney Int 2003;64:84456.

82. Goumenos DS, Tsakas S, El Nahas AM, Alexandri S, Oldroyd S, Kalliakmani P, et al. Transforming growth factor-beta(1) in the kidney and urine of patients with glomerular disease and proteinuria. Nephrol Dial Transplant 2002;17:2145-52.

83. Yamamoto T, Noble NA, Cohen AH, Nast CC, Hishida A, Gold LI, et al. Expression of transforming growth factor-beta isoforms in human glomerular diseases. Kidney Int 1996;49:461-9.

84. Strehlau J, Schachter AD, Pavlakis M, Singh A, Tejani A, Strom TB. Activated intrarenal transcription of CTLeffectors and TGF-beta 1 in children with focal segmental glomerulosclerosis. Kidney Int 2002;61:90-5.

85. Rivarola EW, Moyses-Neto M, Dantas M, Da-Silva CG, Volpini R, Coimbra TM. Transforming growth factor beta activity in urine of patients with type 2 diabetes and diabetic nephropathy. Braz J Med Biol Res 1999;32:1525-8.

86. Vasconcelos MA, Bouzada MC, Silveira KD, Moura LR, Santos FF, Oliveira JM, et al. Urinary levels of TGF-beta 1 and of cytokines in patients with prenatally detected nephrouropathies. Pediatr Nephrol 2011;26:739-47.

87. Eardley KS, Kubal C, Zehnder D, Quinkler M, Lepenies J, Savage CO, et al. The role of capillary density, macrophage infiltration and interstitial scarring in the pathogenesis of human chronic kidney disease. Kidney Int 2008;74:495-504.

88. Stephan M, Conrad S, Eggert T, Heuer R, Fernandez S, Huland $\mathrm{H}$. Urinary concentration and tissue messenger RNA expression of monocyte chemoattractant protein-1 as an indicator of the degree of hydronephrotic atrophy in partial ureteral obstruction. J Urol 2002;167:1497502.

89. Rovin BH, Song H, Birmingham DJ, Hebert LA, Yu CY, Nagaraja HN. Urine chemokines as biomarkers of human systemic lupus erythematosus activity. J Am Soc Nephrol 2005;16:467-73.

90. Stangou M, Alexopoulos E, Papagianni A, Pantzaki A, Bantis C, Dovas S, et al. Urinary levels of epidermal growth factor, interleukin-6 and monocyte chemoattractant protein-1 may act as predictor markers of renal function outcome in immunoglobulin A nephropathy. Nephrology (Carlton) 2009;14:61320.

91. Qi W, Chen X, Polhill TS, Sumual S, Twigg S, Gilbert RE, et al. TGF-beta1 induces IL- 8 and MCP-1 through a connective tissue growth factor-independent pathway. Am J Physiol Renal Physiol 2006;290:F703-9.

92. Wang SN, Hirschberg R. Growth factor ultrafiltration in experimental diabetic nephropathy contributes to interstitial fibrosis. Am J Physiol Renal Physiol 2000;278:F554-60.

93. Donadelli R, Abbate M, Zanchi C, Corna D, Tomasoni $\mathrm{S}$, Benigni A, et al. Protein traffic activates NF-kB gene signaling and promotes MCP-1-dependent interstitial inflammation. Am J Kidney Dis 2000;36:1226-41.

94. Wang Y, Chen J, Chen L, Tay YC, Rangan GK, Harris DC. Induction of monocyte chemoattractant protein-1 in proximal tubule cells by urinary protein. J Am Soc Nephrol 1997;8:1537-45. 
95. Shimizu H, Maruyama S, Yuzawa Y, Kato T, Miki Y, Suzuki $\mathrm{S}$, et al. Anti-monocyte chemoattractant protein-1 gene therapy attenuates renal injury induced by protein-overload proteinuria. J Am Soc Nephrol 2003;14:1496-505.

96. Liao TD, Yang XP, Liu YH, Shesely EG, Cavasin MA, Kuziel WA, et al. Role of inflammation in the development of renal damage and dysfunction in angiotensin IIinduced hypertension. Hypertension 2008;52:256-63.

97. Tesch GH, Maifert S, Schwarting A, Rollins BJ, Kelley VR. Monocyte chemoattractant protein 1-dependent leukocytic infiltrates are responsible for autoimmune disease in MRL-Fas(lpr) mice. J Exp Med 1999;190:1813-24.
98. Wada T, Yokoyama H, Su SB, Mukaida N, Iwano M, Dohi K, et al. Monitoring urinary levels of monocyte chemotactic and activating factor reflects disease activity of lupus nephritis. Kidney Int 1996;49:761-7.

99. Tucci M, Barnes EV, Sobel ES, Croker BP, Segal MS, Reeves WH, et al. Strong association of a functional polymorphism in the monocyte chemoattractant protein 1 promoter gene with lupus nephritis. Arthritis Rheum 2004;50:1842-9.

100.Noris M, Bernasconi S, Casiraghi F, Sozzani S, Gotti E, Remuzzi G, et al. Monocyte chemoattractant protein- 1 is excreted in excessive amounts in the urine of patients with lupus nephritis. Lab Invest 1995;73:804-9. 